\title{
REVERSAL OF CISPLATIN-INDUCED MEMORY IMPAIRMENT BY GALLIC ACID IN EXPERIMENTAL RAT MODEL
}

\author{
SUCHARITA PATEL, CHANDAN HM, KRISHNA KL*, NANDINI HS, ABHINAV RAJ GHOSH, BHOOSHITHA AN
}

Department of Pharmacology, JSS College of Pharmacy, JSS Academy of Higher Education and Research, Mysuru, Karnataka, India. Email: klkrishna@jssuni.edu.in

Received: 02 January 2020, Revised and Accepted: 25 February 2020

\begin{abstract}
Objective: The objective of the study was to evaluate the protective effect of gallic acid on cisplatin-induced memory impairment (MI) in the rat model.

Methods: Five groups of Wistar albino rats $(n=6)$ were employed and the duration of the study was 22 days, excluding the pre-treatment period. Animals were pretreated with gallic acid for a period of 5 days and continued daily ( $200 \mathrm{mg} / \mathrm{kg}$ ) for 22 days. The cisplatin ( $3 \mathrm{mg} / \mathrm{kg}$ ) was given once in a week for 3 consecutive weeks to induce MI, whereas donepezil was used as standard. The evaluation was done by a change in body weight, memory activity by Morris water maze (MWM), locomotor activity by actophotometer, antioxidant activity by thiobarbituric acid reactive substance (TBARS), glutathione (GSH), and estimation of acetylcholinesterase (AChE) activity in brain homogenate.
\end{abstract}

Results: Administration of cisplatin has induced MI by increasing in escape latency time, decrease in time spent in the target quadrant in the MWM task and it was reversed by gallic acid treatment. Decreased locomotor activity by cisplatin was also increased by gallic acid when tested by actophotometer. Cisplatin administration has induced oxidative stress by increasing TBARS and decreasing GSH levels. Gallic acid due to its proven antioxidant activity reversed the effects of cisplatin. The AChE level was significantly increased in the control group, whereas treatment groups have shown a decrease in AChE level.

Conclusion: Gallic acid may serve as a primary agent to treat the cognitive impairment and oxidative stress associated memory dysfunctions. However, more extensive studies are needed before utilization in the clinical trial.

Keywords: Alzheimer's disease, Morris water maze, Lipid peroxidation, Glutathione, cisplatin, Gallic acid.

(C) 2020 The Authors. Published by Innovare Academic Sciences Pvt Ltd. This is an open access article under the CC BY license (http://creativecommons. org/licenses/by/4. 0/) DOI: http://dx.doi.org/10.22159/ajpcr.2020.v13i4.36932

\section{INTRODUCTION}

Around 24 million people are suffering from Alzheimer's disease (AD) across the globe [1]. Cognition is the term noted with a decrease in the memory function by undergoing several pathophysiological conditions such as oxidative stress, mitochondrial dysfunction, lipid peroxidation, and cell apoptosis. These alterations in the body will lead to the generation of free radicals and due to decreased antioxidant levels; these cause cognitive impairment $[2,3]$. In a recent survey conducted by the World Health Organization, it has been reported that 1.2 billion aged geriatric population will be suffering from $\mathrm{AD}$, living in low- and middle-income countries by the year 2025 [4].

Several class of drugs which have been used in the market till date; however, early diagnosis and withdrawal are essential in prevention drug-induced dementia and delirium [5]. The "Green" movement in Western society has changed attitudes in the general population who now conceive naturally derived substances and extracts as being inherently safer and more desirable than synthetic chemical products, with the net effect of the increase in sales of herbal preparations. About $80 \%$ of people in developing countries rely on phytomedicine for primary health care for men and livestock [6]. Cisplatin has peak toxic index, including renal, neuropathy being dose limits, one of the currently well-known chemotherapeutic drugs in use. Some literature supports the memory impairment (MI) ability of cisplatin in experimental animal models [7].

One of the highly used antioxidants in plant products is gallic acid, which comes under the class of polyphenols and acts as a secondary metabolite. Tea, which has many traditional values in culture and has many pharmacological effects through receptor relaxation, also contains the polyphenolic substances and major content resides with gallic acid [8]. Biologically, contains antitumor activity and has been analyzed with chemo-protective action in cell line studies $[8,9]$. The possible neuroprotective effect of gallic acid is against the neurotoxicity by enhancing the NMDA receptor sensitivity. This complete pathway is activated due to the glutamate excitotoxicity and leads to cerebral ischemia which further leads to excessive calcium intake and meanwhile causing an increase in intracellular calcium levels by calcium accumulation-induced neuronal apoptosis [10,11]. Its usefulness in MI induced by cisplatin is not yet reported, so the present study is undertaken with that objective to test it in the experimental animal model.

\section{METHODS}

\section{Animals}

All experimental animals (Wistar male rats) were procured from Biogen Ltd., Bengaluru, and animals were approved by IAEC of JSS College of Pharmacy, Mysuru (Proposal no. 294/2018). Animals were acclimatized for the laboratory condition for at least 1 week before the start of the experiment.

\section{Study protocol}

Five groups of Wistar albino rats were employed in this study, each group consists of six animals. Animals were pretreated with gallic acid for 5 days, to attain the neuroprotection, which is a key objective of the study. After 5 days of pre-treatment with gallic acid, the treatment was continued for 22 days. Cisplatin was given once in a week at a dose of $3 \mathrm{mg} / \mathrm{kg}$ for 3 consecutive weeks. The evaluation was done by a change in body weight, MI activity by Morris water maze (MWM) task, locomotor activity by actophotometer, antioxidant, and acetylcholinesterase (AChE) estimation in brain homogenate (Table 1). 
Table 1: Details of the study protocol for the evaluation of the protective effect of gallic acid on cisplatin [12]-induced MI in rats

\begin{tabular}{|c|c|c|}
\hline Groups & Treatment, dose, duration, and induction of MI & Evaluation \\
\hline Normal & Oral $0.5 \%$ sodium CMC (vehicle) $(1 \mathrm{ml} / \mathrm{kg}$ ) for 22 days & Behavioral parameters \\
\hline Control & $\begin{array}{l}\text { Cisplatin }(3 \mathrm{mg} / \mathrm{kg})(12) \text { by i.p. on } 7^{\text {th }}, 14^{\mathrm{th}} \text {, and } 21^{\text {st }} \text { days and } \\
\text { oral vehicle }(1 \mathrm{ml} / \mathrm{kg}) \text { daily for } 22 \text { days }\end{array}$ & Bodyweight [13] \\
\hline Standard & $\begin{array}{l}\text { Cisplatin ( } 3 \mathrm{mg} / \mathrm{kg} \text { ) by i.p. on } 7^{\text {th }}, 14^{\text {th }} \text {, and } 21^{\text {st }} \text { days and oral } \\
\text { donepezil ( } 5 \mathrm{mg} / \mathrm{kg} \text { ) daily for } 22 \text { days }\end{array}$ & Actophotometer [17-19] \\
\hline Gallic acid & $\begin{array}{l}\text { Cisplatin }(3 \mathrm{mg} / \mathrm{kg}) \text { by i.p. on } 7^{\text {th }}, 14^{\text {th }} \text {, and } 21^{\text {st }} \text { days and oral } \\
\text { gallic acid }(200 \mathrm{mg} / \mathrm{kg}) \text { daily for } 22 \text { days }\end{array}$ & $\begin{array}{l}\text { Biochemical parameters } \\
\text { Thiobarbituric acid reactive substance (LPO) [20,21] } \\
\text { Reduced GSH [22] Acetyl cholinesterase's estimation [23] }\end{array}$ \\
\hline
\end{tabular}

MWM: Morris water maze, MI: Memory impairment, GSH: Glutathione

Table 2: Evaluation of the protective effect of gallic acid on cisplatin-induced MI in rats (bodyweight changes)

\begin{tabular}{llll}
\hline Groups & Day 0 & Day 7 & Day 14 \\
\hline Normal & $203.33 \pm 0.817$ & $206.33 \pm 0.958$ & $224 \pm 1.039$ \\
Control & $208.33 \pm 0.873$ & $215 \pm 0.939$ & $225 \pm 0.980$ \\
Standard & $196.5 \pm 0.8174$ & $208.1 \pm 0.858$ & $229.6 \pm 1.054$ \\
Gallic acid & $204.5 \pm 0.827$ & $222.1 \pm 0.940$ & $22.5 \pm 0.929$ \\
\hline
\end{tabular}

Data were expressed as Mean \pm SEM, $\mathrm{n}=6$, two-way ANOVA followed by Bonferroni post-test. *Significant when compared to normal group (p<0.01), ${ }^{\text {significant when }}$ compared to the control group ( $\mathrm{p}<0.01),{ }^{+}$significant when compared to the standard group $(\mathrm{p}<0.01)$.MI: Memory impairment

Table 3: Evaluation of the protective effect of gallic acid on cisplatin-induced MI in rats on MWM task (latency time in s)

\begin{tabular}{llllll}
\hline Groups & Day 0 & Day 4 & Day 7 & Day 14 & Day 21 \\
\hline Normal & $51.33 \pm 0.446$ & $14.66 \pm 0.511$ & $13.66 \pm 0.406$ & $6.88 \pm 0.27$ & $7.66 \pm 0.293$ \\
Control & $56.33 \pm 0.498$ & $10.66 \pm 0.410^{*}$ & $27.5 \pm 0.419^{*}$ & $39.5 \pm 0.350^{*}$ & $46.83 \pm 0.403^{*}$ \\
Standard & $55.5 \pm 0.418$ & $11.16 \pm 0.390^{*}$ & $19.5 \pm 0.421^{* \#}$ & $16 \pm 0.320^{* \#}$ & $15.16 \pm 0.304^{*}$ \\
Gallic acid & $55.66 \pm 0.764$ & $11.16 \pm 0.504^{*}$ & $16.66 \pm 0.364^{* \#}$ & $15.83 \pm 0.403^{* \#}$ & $14.33 \pm 0.4060^{* *+}$ \\
\hline
\end{tabular}

Data were expressed as Mean \pm SEM, $\mathrm{n}=6$, two-way ANOVA followed by Bonferroni post-test. *Significant when compared to normal group (p<0.01), ${ }^{\text {significant when }}$ compared to the control group ( $<<0.01)$, ${ }^{+}$significant when compared to the standard group ( $\left.<<0.01\right)$. MI: Memory impairment, MWM: Morris water maze

Table 4: Evaluation of the protective effect of gallic acid on cisplatin-induced MI in rats on MWM task (time spent in the target quadrant in s)

\begin{tabular}{llll}
\hline Groups & Day $\mathbf{7}$ & Day $\mathbf{1 4}$ & Day $\mathbf{2 1}$ \\
\hline Normal & $31.33 \pm 0.3605$ & $31.83 \pm 0.371951$ & $30.50 \pm 0.270286$ \\
Control & $14.66 \pm 0.33787$ & $13.16 \pm 0.308937^{*}$ & $8.333 \pm 0.337452^{*}$ \\
Standard & $25.33 \pm 0.4480$ & $27.50 \pm 0.433062^{* \#}$ & $28.50 \pm 0.256196^{* \#}$ \\
Gallic acid & $23.83 \pm 0.4327$ & $26.83 \pm 0.409581^{* \#}$ & $29.50 \pm 0.276575^{* *}$ \\
\hline
\end{tabular}

Data were expressed as Mean \pm SEM, $n=6$, two-way ANOVA followed by

Bonferroni post-test. *Significant when compared to normal group $(\mathrm{p}<0.01)$.

"Significant when compared to the control group $\mathrm{p}<0.01$ ). MI: Memory impairment, MWM: Morris water maze

\section{RESULTS}

\section{Bodyweight changes}

There were no significant changes observed in body weight changes among all the groups and this shows that cisplatin has no effects on body weight changes (Table 2).

\section{Escape latency time (ELT) in mwm task}

There was an increase in ELT in a control group of animals gradually as the dose of cisplatin increases. Hence, it showed that disease has been induced in the animals. Meanwhile, ELT was decreased in the gallic acid-treated group when compared to the control group (69\%) and it was significant and comparable to the standard drug (Table 3).

Time spent in target quadrant (TSTQ) in mwm task

There was a significantly decreased TSTQ in the control group when compared to the normal group, which indicates the MI induced by cisplatin. Standard, as well as gallic acid, reversed the TSTQ to normal at the end of the study progressively and the activity was found to be significant (Table 4).

\section{Locomotor activity}

The locomotor activity is shown in Table 5, which was determined to test the effect of the drug on motor activity. Cisplatin administration has decreased the locomotor activity significantly when compared with that of the normal group of animals. Gallic acid treatment reversed the effect of cisplatin significantly and the same as that of standard.

\section{Antioxidant enzymes (TBARs/lipid peroxidation)}

LPO was significantly increased in the control group when compared with the normal group, which supports the oxidative stress induced by cisplatin, may be responsible for cognitive impairment. Treatment with gallic acid and standard reversed the increased LPO levels which were significant when compared with the control group animals (Table 6).

Antioxidant enzymes (reduced glutathione [GSH])

The same was observed in GSH activity also, it was significantly decreased in the control group when compared with the normal group. Administration of gallic acid has shown a reversal of GSH level as that of the standard and it was significant when compared to the control group (Table 6).

\section{AChE activity}

The AChE level was significantly increased in the control group when compared with the normal group and it indicates the less amount of acetylcholine (may be responsible for MI). The AChE levels were decreased in the test group in comparison with the control group and it was found to be significant (Table 7).

\section{DISCUSSION}

The loss of memory in a short period is categorized in Alzheimer's like disease or cognitive impairments. In the present study, cisplatin has been used as a disease-inducing drug, as it has a high potent action on brain cells and has several pathophysiological actions which, in turn, 
Table 5: Evaluation of the protective effect of gallic acid on cisplatin-induced MI in rats on locomotor activity using actophotometer (locomotor activity in s)

\begin{tabular}{llll}
\hline Groups & Day 0 & Day 7 & Day 14 \\
\hline Normal & $423.00 \pm 1.39$ & $410.00 \pm 1.58$ & $369.00 \pm 1.88$ \\
Control & $325.00 \pm 1.47$ & $325.30 \pm 1.47^{*}$ & $304.00 \pm 1.67^{*}$ \\
Standard & $357.83 \pm 1.37$ & $342.83 \pm 1.59^{* \#}$ & $310.00 \pm 1.61^{* \#}$ \\
Gallic acid & $370.00 \pm 1.75$ & $355.00 \pm 1.88^{* \#+}$ & $391.00 \pm 2.31^{*++}$ \\
\hline
\end{tabular}

Data were expressed as MEAN \pm SEM, $n=6$, two-way ANOVA followed by Bonferroni post-test.*Significant when compared to normal group ( $\mathrm{p}<0.01$ ), " Significant when compared to the control group ( $\mathrm{p}<0.01)$, + significant when compared to the standard group $(\mathrm{p}<0.01)$. MI: Memory impairment

Table 6: Evaluation of the protective effect of gallic acid on cisplatin-induced MI in rats on endogenous antioxidant enzymes

\begin{tabular}{lll}
\hline Groups & $\begin{array}{l}\text { TBAR's (nmole/MDA } \\
\text { per mg of protein) }\end{array}$ & $\begin{array}{l}\text { GSH }(\boldsymbol{\mu M} / \mathbf{m g} \text { of a } \\
\text { brain protein) }\end{array}$ \\
\hline Normal & $1.55 \pm 0.09$ & $75.21 \pm 0.31$ \\
Control & $6.45 \pm 0.14^{*}$ & $24.80 \pm 0.32^{*}$ \\
Standard & $4.52 \pm 0.11^{*} \#$ & $69.21 \pm 0.44^{\#}$ \\
Treatment & $3.64 \pm 0.11^{*} \#$ & $61.75 \pm 0.36^{* \#}$ \\
\hline
\end{tabular}

Data were expressed as Mean \pm SEM, $n=6$, two-way ANOVA followed by

Bonferroni post-test. *Significant when compared to normal group $(\mathrm{p}<0.01)$,

"significant when compared to the control group $(\mathrm{p}<0.01)$. MI: Memory

impairment, GSH: Glutathione

Table 7: Evaluation of the protective effect of gallic acid on cisplatin-induced MI in rats (acetylcholinesterase activity in brain homogenate)

\begin{tabular}{ll}
\hline Groups & AChE $(\boldsymbol{\mu m o l e s})$ \\
\hline Normal & $66.911 \pm 0.312$ \\
Control & $106.333 \pm 0.417^{*}$ \\
Standard & $76.005 \pm 0.344^{\#}$ \\
Treatment & $73.346 \pm 0.420^{* \#}$ \\
\hline
\end{tabular}

Data were expressed as Mean \pm SEM, $n=6$, two-way ANOVA followed by

Bonferroni post-test. *Significant when compared to normal group $(\mathrm{p}<0.01)$,

"significant when compared to the control group ( $\mathrm{p}<0.01)$. MI: Memory

impairment. AChE: Acetylcholinesterase

cause the apoptosis/programmed cell death, mitochondrial dysfunction, excitotoxicity, and reactive oxygen species (ROS) generation. If excitotoxicity plays a key role in neurological disorders, the possibility of glutamate blockade agents/glutamate antagonist to decrease the excitotoxicity caused by glutamate activation [23]. In the experimental protocol, animals were pretreated with gallic acid for a period of 5 days, to attain the neuroprotection, which is a key objective of the study. After 5 days of pre-treatment with gallic acid, the treatment drug was given daily once $(200 \mathrm{mg} / \mathrm{kg})$ with accurate timings to maintain the bioavailability of the drug. The induction drug, cisplatin, was given once in a week with a dose of $3 \mathrm{mg} / \mathrm{kg}$ for 3 consecutive weeks. The animals were subjected to acquisition trials and assessments, wherein there was an evident decrease in the ELT in the control group when compared to the normal group that means the cognitive impairment was induced in the animals on $7^{\text {th }}, 14^{\text {th }}$, and $21^{\text {st }}$ days of the treatment period. Before the biochemical estimation, animals were subjected to behavior parameters to analyze drug activity. Actophotometer was done to analyze the motor coordination of the animal, as cisplatin affects the motor functions, it is digital activity capturing device and is mostly used for central nervous system (CNS) acting drugs for evaluating the locomotor action in small animals. The index for CNS depression in the animal was evaluated by their decreased scores, where locomotor activity in the control group has shown a significant decrease when compared to the normal group. Body weight indicates the health of the animal, and in this study, as cisplatin has a high affinity to a central system in the body and affects the body weight, the evaluation was done through recorded average values calculated, and statistical analysis should be done for " $p$ " values. The body weight has decreased moderately when compared between normal and control groups. Biochemical estimations play a significant role in research, collection of tissue and homogenate sample can be used for biochemical estimations. In detail, AChEs are the enzymes that are responsible for breaking Ach into acetyl and choline. Wherein, thiobarbituric acid reactive substance/ lipid peroxidation also refers to the oxidative process in the brain cells and increases the ROS and increases cell apoptosis through several pathophysiological pathways [24-26]. Meanwhile, GSH, reduced GSH which has the primary function to alleviate the antioxidant process in the body, shows the oxidative index and analyzes the antioxidant levels, as oxidative stress the primary step for mitochondrial dysfunction and an increase of ROS, which further leads to cell death or neuronal cell death $[27,28]$. Gallic acid shows a promising role in reducing the oxidative process as it has potent antioxidant properties. In this study, gallic acid acts through antioxidant and inflammatory pathways, hence promoting its neuroprotective effect in animal models. Hence, it may be concluded that gallic acid may serve as a primary agent to treat cognitive impairment and oxidative stress associated memory dysfunctions. However, more extensive studies are needed before utilization in a clinical trial. Further, it should be studied in the aspects of effectiveness with a suitable explanation of molecular mechanisms in rodents as well as non-rodent species.

\section{CONCLUSION}

The study was designed to understand the possible role of gallic acid in cisplatin-induced MI in the rat model. The result of the present study reveals the protective effect of gallic acid on MI induced by cisplatin. Hence, it may be concluded that gallic acid may serve as a primary agent to treat cognitive impairment and oxidative stress associated memory dysfunctions. However, more extensive studies are needed in rodent as well as non-rodent species to understand its molecular mechanism of action.

\section{AUTHORS' CONTRIBUTIONS}

The author Sucharita Patel worked on the rat model of MI induced by Cisplatin. Dr. KL Krishna contributed to conception of project, design, and critical revision. The statistical analysis was done by Nandini HS, Chandan HM, Abhinav Raj Ghosh, and Bhooshitha AN worked on the interpretation of data and drafting of manuscript.

\section{CONFLICTS OF INTEREST}

The authors have no conflicts of interest.

\section{AUTHORS' FUNDING}

This project was funded by the JSS Academy of Higher Education and Research.

\section{REFERENCES}

1. Ballard C, Gauthier S, Corbett A, Brayne C, Aarsland D, Jones E. Alzheimer's disease. Lancet 2011;377:1019-31.

2. American Psychiatric Association. Diagnostic and Statistical Manual of Mental Disorders. Arlington, VA, USA: American Psychiatric Publishing; 2013.

3. Chen RC, Liu CL, Lin MH, Peng LN, Chen LY, Liu LK, et al. Nonpharmacological treatment reducing not only behavioral symptoms, but 
also psychotic symptoms of older adults with dementia: A prospective cohort study in Taiwan. Geriatr Gerontol Int 2014;14:440-6.

4. World Health Organization. Active Aging: A Policy Framework; 2002. Available from: https://www.who.int/ageing/publications/active ageing/en.

5. The Healthline Editorial Team, Dementia and Alzheimer's: What are the Differences? 2016. Available from: https://www.alzheimers.net/ difference-between- Alzheimer's-and-dementia.

6. Kumar GP, Khanum F. Neuroprotective potential of phytochemicals. Pharmacogn Rev 2012;6:81.

7. Dasari S, Tchounwou PB. Cisplatin in cancer therapy: Molecular mechanisms of action. Eur J Pharmacol 2014;740:364-78

8. Isuzugawa $\mathrm{K}$, Inoue $\mathrm{M}$, Ogihara Y. Catalase contents in cells determine sensitivity to the apoptosis inducer gallic acid. Biol Pharm Bull 2001;24:1022-6.

9. Kim YJ. Antimelanogenic and antioxidant properties of gallic acid. Biol Pharm Bull 2007;30:1052-5.

10. Kroes BV, Van den Berg AJ, Van Ufford HQ, Van Dijk H, Labadie RP. Anti-inflammatory activity of gallic acid. Plant Med 1992;58:499-504.

11. Hajipour S, Sarkaki A, Farbood Y, Eidi A, Mortazavi P, Valizadeh Z. Effect of gallic acid on dementia type of Alzheimer disease in rats: Electrophysiological and histological studies. Basic Clin Neurosci 2016;7:97.

12. Morris R. Developments of a water-maze procedure for studying spatial learning in the rat. J Neurosci Methods 1984;11:47-60.

13. Ellman GL, Courtney KD, Andres V Jr., Featherstone RM. A new and rapid colorimetric determination of acetylcholinesterase activity. Biochem Pharmacol 1961;7:88-95.

14. Wever EG. Water temperature as an incentive to swimming activity in the rat. J Comp Psychol 1932;14:219.

15. Woods PJ, Holland CH. Performance on a black-white discrimination problem in a water maze as influenced by water temperature and swimming ability. Psychol Rep 1961;9:433-9.

16. Bhosale UA, Yegnanarayan R, Pophale PD, Zambare MR, Somani RS. Study of central nervous system depressant and behavioral activity of an ethanol extract of Achyranthes aspera (Agadha) in different animal models. Int J Appl Basic Med Res 2011;1:104

17. Kadam U, Bhosale A. Zopiclone (cyclopyrrolone): A novel hypnosedative; hypnosedation caused by zopiclone does not impair memory-learning in albino mice. CNS Neurosci Ther 2010;16:e180-4.

18. Thornburg JE, Moore KE. A comparison of effects of apomorphine and ET495 on locomotor activity and circling behaviour in mice. Neuropharmacology 1974;13:189-97.

19. Garcia JM, Scherer T, Chen J, Guillory B, Nassif A, Papusha V, et al. Smith, inhibition of cisplatin-induced lipid catabolism and weight lossby ghrelin in male mice. Endocrinology 2013;154:3118-29.

20. Ellman GL, Tissue sulfhydryl groups. Arch Biochem Biophys $1959 ; 82 ; 70-7$

21. Uchiyama M, Mihara M. Determination of malonaldehyde precursor in tissues by thiobarbituric acid test. Anal Biochem 1978;86:271-8

22. Beutler E. Improved method for the determination of blood glutathione. J Lab Clin Med 1963;61:882-8.

23. Hague SM, Klaffke S, Bandmann O, Neurodegenerative disorders: Parkinson's disease and Huntington's disease. J Neurol Neurosurg Psychiatry 2005;76:1058-63.

24. Baldeiras I, Santana I, Proença MT, Garrucho MH, Pascoal R, Rodrigues A, et al. Oxidative damage and mitochondrial dysfunction in patients with mild cognitive impairment and Alzheimer's disease. Alzheimer's Dement 2010;6:S503-4.

25. Rikans LE, Hornbrook KR. Lipid peroxidation, antioxidant protection and aging. Biochim Biophys 1997;1362:116-27.

26. Ighodaro OM, Akinloye OA. First line defence antioxidants-superoxide dismutase (SOD), catalase (CAT) and glutathione peroxidase (GPX): Their fundamental role in the entire antioxidant defence grid. Alexandria J Med 2018;54:287-93.

27. Wagle N, Nagarjuna S, Sudheer A, Roopesh C, Sapkota HP, Bahadur N, et al. Evaluation of immunomodulatory activity of petroleum ether extract of seeds of Pithecellobium dulce in Wistar rats. Int J Pharm Pharm Sci 2015;7:471-9.

28. Purushothaman BP, Valsan G, Kuttan R. Oxycarotenoid lutein reverses the toxicity induced by carbofuran in wistar rats. Int J Pharm Pharm Sci 2018; $10: 10-5$ 